\title{
Congruência Semântica: implicações didáticas no ensino da regra dos sinais
}

\author{
Selma Felisbino \\ Hillesheim (D) \\ Secretaria de Estado da \\ Educação/SC \\ פselmafh@yahoo.com.br \\ Méricles Thadeu Moretti (D) \\ Universidade Federal de Santa \\ Catarina \\ వmthmoretti@gmail.com
}

\section{Semantic congruence: didactic implications in teaching sign rules}

\begin{abstract}
There are some problems related to teaching sign rules from a didactic perspective. The commercial model, which is often used to teach additive properties, can contribute to the emergence of obstacles in teaching the multiplicative properties of integers. In terms of semantic congruence, which is a semiotic and cognitive phenomenon that measures the degree of transparency between two semiotic representations, the commercial model is strongly criticized due to the codified association between verbs and signs. We adopted herein a qualitative research approach in which we analyzed the semantic congruence in teaching sign rules to seventh grade elementary school students. As result, we indicate that the teaching situations in which semantic congruence differed from referential equivalence required higher cognitive costs when compared to the situations in which semantic congruence coincides with referential equivalence. The level of transparency between two semiotic representations needs to be considered in sign rules' teaching and learning processes.
\end{abstract}

Key words: Sign rules; Semantic congruence; Teaching; Negative numbers.

\begin{abstract}
Resumo
O ensino da regra dos sinais, sob o ponto de vista didático, encontra problemas. O modelo comercial, muito utilizado para o ensino das propriedades aditivas, pode contribuir para a formação de obstáculos para o ensino das propriedades multiplicativas dos inteiros relativos. O modelo comercial encontra no fenômeno da congruência semântica, que é um fenômeno semiótico e cognitivo que mede o grau de transparência entre duas representações semióticas, uma forte oposição por conta de uma associação codificada entre verbos e sinais. Trata-se de uma pesquisa qualitativa, propondo-se a analisar a congruência semântica em situações de ensino da regra dos sinais numa turma do 70 ano do ensino fundamental. Como resultado, aponta-se que as situações de ensino em que a congruência semântica se destacou da equivalência referencial, exigiu um custo cognitivo maior quando comparado aos casos em que a congruência semântica incidiu com a equivalência referencial. Percebe-se que o nível de transparência entre duas representações semióticas precisa ser considerado no processo de ensino e aprendizagem da regra dos sinais.
\end{abstract}

Palavras-chave: Regra dos Sinais; Congruência Semântica; Ensino; Números Negativos. 


\section{INTRODUÇÃO}

O processo de ensino e aprendizagem dos números inteiros relativos, nos anos finais do ensino fundamental, enfrenta problemas que acabam repercutindo ao longo da trajetória escolar dos alunos. Muitas dificuldades podem ser percebidas nesse processo; dentre elas destacaremos os fenômenos da congruência e da não congruência semântica e o modelo comercial. De acordo com [10], o modelo comercial usado para facilitar a compreensão das propriedades aditivas constitui-se como um obstáculo à compreensão da multiplicação desses números.

Por meio do modelo metafórico, o aluno é facilmente convencido de que se ele deve três reais $(-3)$ para sua mãe e deve dois reais $(-2)$ para o seu pai, ele está devendo para os seus pais a quantia de cinco reais $(-5)$. Contudo, dificilmente será convencido do mesmo, ao tentar entender que a multiplicação de $(-3)$ por $(-2)$ tem por produto +6 , utilizando essa mesma ideia. Como uma dívida multiplicada por outra dívida pode tornar-se num ganho? "Nessas condições, não se está introduzindo um falso contrato didático quando se utiliza o modelo concreto para apresentar o conjunto dos números relativos?" [4, p. 183, grifos do autor]. O modelo comercial pode facilitar o entendimento do aluno a respeito dos problemas aditivos de números relativos, assim como os que aparecem nos livros didáticos, porém essa abordagem pode trazer dificuldades para a compreensão de problemas multiplicativos.

Outra questão a ser analisada diz respeito à congruência e a não congruência semântica [6], encontrada no ensino das operações com os números inteiros relativos. A adição desses números nem sempre representa um ganho, a subtração nem sempre representa uma perda e a multiplicação de dois números negativos não pode ser explicada usando a ideia de adição de parcelas iguais. As variações de congruência e não congruência nos problemas que exigem a conversão dos registros de representações semióticas implicam uma distância cognitiva considerável nas situações de ensino da regra dos sinais.

Percebe-se que, atualmente, do ponto de vista matemático, a regra dos sinais não causa nenhuma dificuldade ou estranheza, após ter sido demonstrada por Hankel em $1867^{1}$. Entretanto, do ponto de vista didático-pedagógico muitos obstáculos ainda precisam ser superados. Os fenômenos da congruência semântica e a presença do modelo comercial nas situações de ensino podem ser encontrados nas respostas dos testes aplicados por [12] e por [11] a alunos do $7^{\circ}$ ano do ensino fundamental. Assumindo uma abordagem qualitativa como forma de trabalho, propomo-nos a analisar algumas das respostas apresentadas pelos alunos, segundo esses autores, procurando destilar

\footnotetext{
${ }^{1}$ A regra da multiplicação de números negativos foi demonstrada por Hermann Hankel no seu livro "Théorie des complexen Zahlsysteme" em 1867. Em Hillesheim e Moretti (2016) encontra-se uma retrospectiva histórica do surgimento da regra de sinais.
} 
as situações nas quais a congruência semântica se destacou da equivalência referencial e os casos em que o modelo comercial insiste em aparecer no ensino da regra dos sinais.

\section{O MODELO COMERCIAL E A CONGRUÊNCIA SEMÂNTICA}

A regra dos sinais para a multiplicação é pura invenção da mente humana. Prova disso foi a demonstração do Teorema de Hankel, que fez cair por terra a ideia da existência de exemplos práticos que explicam os números inteiros relativos pelo uso do modelo metafórico. A postura assumida por Hankel, desprendendo-se da opinião a favor da ciência, possibilitou resolver, definitivamente, o problema do ponto de vista matemático, sobre a regra dos sinais, ao prolongar para os números negativos a propriedade da distributividade, há muitos anos utilizada para os positivos. Percebe-se, então, que a ciência opõe-se à opinião. "A opinião pensa mal; não pensa: traduz necessidades em conhecimentos. Ao designar os objetos pela utilidade, ela se impede de conhecê-los" [1, p. 18]. Portanto, a legitimação da regra dos sinais poderia ter sido resolvida muito tempo antes, se os matemáticos tivessem se libertado da opinião, ou seja, do entendimento do número como coisa, "[. . .] como grandeza, como objeto dotado de substância. Tal concepção torna difícil a compreensão do número negativo ser menor que zero, uma vez que número é quantidade e o zero é a ausência de quantidade" [15, p. 19].

Glaeser [10] nos provoca ao dizer que o "bom modelo" utilizado para ensinar as propriedades aditivas, baseado no "modelo comercial", associando a ideia de ganho a um número positivo e ao número negativo ao de uma perda, pode trazer riscos ao ensino das propriedades multiplicativas desses números. Dessa forma, o ensino dos números relativos precisa sofrer mudanças, não podendo mais se prender somente nos exemplos baseados em situações cotidianas, haja vista que, historicamente, 0 número negativo não surgiu num contexto aritmético, mas sim num contexto algébrico.

\footnotetext{
Contudo, o ensino atual dos números inteiros se introduz em um contexto aritmético, tanto nas situações que introduz como nas técnicas que utilizam para resolvê-las, contexto em que não são necessários como estratégia de resolução. Como consequência, o estabelecimento de suas regras de cálculo fica totalmente a mercê do modelo concreto que se utiliza para introduzi-los, e este tratamento didático contribui, todavia, ainda mais para agravar o obstáculo epistemológico [3, p. 13].
}

O modelo comercial, assim denominado por [10], baseia-se em problemas de balanço do tipo crédito/débito, ganho/perda, sobe/desce, presente/futuro, enche/esvazia etc. São modelos concretos, bastante comuns, que associam, por exemplo, ao sinal "+" o ganho e ao sinal "-" a perda. Contudo, esses modelos não têm relação nenhuma 
com a regra dos sinais "menos vezes menos dá mais". O que antes era completamente contextualizado com situações concretas, que poderiam ser vivenciadas e compreendidas pelos alunos, agora na multiplicação não faz nenhum sentido. No entanto,

[. . .] como é concreto e ele facilita muito a compreensão dos relativos no início de sua aprendizagem, os alunos o adotam e querem utilizá-lo enquanto não é mais adaptado: não somente, ele não explica mais nada, mas ele representa mais nada, ele não funciona nem mesmo ao nível do símbolo [4, p. 183].

Michelot ${ }^{2}$, citado por [4], preocupou-se por muito tempo em demonstrar que "a noção do número negativo só pode ser definido corretamente em nível do pensamento formal" [4, p. 183]. Quando o professor faz uso do modelo comercial para explicar as propriedades aditivas desses números, ele procura somente facilitar a apresentação e a aprendizagem, no entanto "[. . .] esse modelo comercial é tão prático, tal que ele é reforçado durante todo o início da aprendizagem que ele se instala definitivamente no espírito do aluno, não mais como um modelo, mas como uma concepção dos relativos" [4, p. 184, grifos do autor].

O processo de ensino e aprendizagem da multiplicação dos números relativos pode encontrar dificuldades se a concepção desses números estiver fundamentada somente em bases concretas [4]. Assim, para que a multiplicação dos números relativos possa ser alcançada e compreendida pelos alunos, de acordo com essa autora, é preciso que ocorra uma reversão desse quadro. Porém, essa concepção está tão bem estabelecida, que ela, nela mesma, constitui um verdadeiro obstáculo para a compreensão das propriedades multiplicativas dos números relativos [4]. A apresentação dos números relativos pautados somente no "modelo comercial" pode trazer prejuízos ao ensino da multiplicação desses números, bem como dificultar a aprendizagem de outros conceitos [4].

Uma análise didática do modelo comercial a partir de $[9,5,6]$, na perspectiva da congruência e da não congruência semântica, faz-nos perceber que procurar substituir uma expressão ou uma representação por outra, que seja referencialmente equivalente, pode trazer constrangimentos quando se trata da multiplicação dos inteiros negativos. Afinal, como uma dívida multiplicada por outra dívida pode transformarse num ganho? Passar da frase: "O produto de dois números inteiros relativos tem como resultado +10 ", para uma das expressões simbólicas: $(-10)(-1) ;(+10) \times(+1)$; $(-2) \times(-5)$ ou $(+2) \times(+5)$ é totalmente diferente. Essas formas de escrita, frase e expressão simbólica, fazem referência a um mesmo objeto matemático, mas não possuem o mesmo significado. A frase expressa o objeto matemático em função das propriedades discursivas e a expressão simbólica em função das propriedades mul-

\footnotetext{
${ }^{2}$ A. Michelot, La notion de zero. Paris: Flammarion, 1969.
} 
tiplicativas. "Uma simples mudança na escrita é suficiente para exibir propriedades diferentes do objeto, mesmo se for mantida a mesma referência" [6, p. 99].

Em certos casos, existe uma correspondência direta e transparente entre os conteúdos a serem substituídos, nesse caso, temos uma situação cognitiva de congruência semântica. Contudo, na maior parte das vezes, nas situações que exigem uma substitutividade, tanto inter-registro quanto intra-registro, não há alguma relação de correspondência direta e os conteúdos parecem ser estranhos e até mesmo não reconhecidos. Temos então, o fenômeno da não congruência semântica [6]. Para que o fenômeno da congruência semântica ocorra, faz-se necessário atender a três condições:

- Correspondência semântica entre as unidades significantes que as constituem.

- Univocidade "semântica" terminal, em que para cada unidade significante elementar de partida, corresponde a uma só unidade significante elementar no registro de chegada.

- A ordem dentro da organização das unidades significativas de partida é mantida na representação de chegada [9, p. 53].

Porém, quando não se cumprem um desses critérios, as representações não são congruentes entre si e a passagem de um sistema de representação a outro não acorre de imediato [9]. Para entender um pouco melhor o que este autor quer dizer a respeito da congruência semântica, comecemos com o seguinte exemplo:

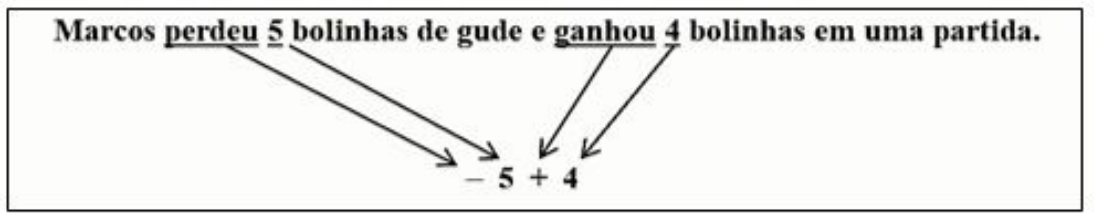

Figura 1: Congruência semântica entre frase e expressão

Pode-se observar, neste exemplo, que a frase e a expressão são semanticamente congruentes, pois os três critérios são atendidos. As unidades significativas da frase são: perdeu, 5 bolinhas, ganhou e 4 bolinhas, que correspondem semanticamente com as unidades significantes da expressão, mantendo-se a mesma ordem dentro das unidades significativas entre os registros de partida da frase (perdeu, 5, ganhou, 4) e de chegada na expressão $(-, 5,+, 4)$. Nota-se, também, a existência da univocidade semântica terminal, pois cada uma das unidades significantes do registro de partida tem correspondência com apenas uma unidade significativa de chegada (perdeu $\rightarrow-$; $5 \rightarrow 5$; ganhou $\rightarrow+, 4 \rightarrow 4$ ). A frase e a expressão aritmética possuem, neste caso, também equivalência referencial. 
Em outras palavras, poderíamos dizer, "de maneira imprecisa", que há congruência semântica quando o aluno reconhece facilmente o objeto matemático, ao passo que, quando esse reconhecimento não ocorre tão facilmente, dizemos que não há congruência semântica.

Podemos ilustrar um caso de não congruência semântica por meio da seguinte situação: "No início de uma tarde de inverno de uma cidade da Serra Gaúcha, os termômetros registram cinco graus Celsius e, no início da noite, os termômetros registraram três graus Celsius negativos. Qual a variação da temperatura nesse período?" Esta situação possui congruência semântica com a expressão $(+5)+(-3)$, cumprindo perfeitamente aos três critérios já explorados acima. Entretanto, a situação e a expressão não são referencialmente equivalentes. A situação descrita acima não possui congruência semântica com a expressão $(-3)-(+5)$, porém a situação e a expressão aritmética são referencialmente equivalentes e conduzem a resolução correta do problema. "Duas expressões diferentes podem ser referencialmente equivalentes sem que sejam semanticamente congruentes. Inversamente, duas expressões podem ser semanticamente congruentes sem que sejam referencialmente equivalentes" [6, $p$. 100].

Na posição de aprendizes, os alunos podem fazer da congruência semântica a condição necessária e, por vezes, suficiente para a conversão entre os diferentes registros de representação semiótica. "Ele encontrará e ficará satisfeito com as substituições que são semanticamente congruentes; por outro lado, ele irá resistir às substituições que não são semanticamente congruentes, mas referencialmente equivalentes" [6, p. 100], contribuindo para o insucesso na resolução do problema. Isso porque "[...] o funcionamento espontâneo do pensamento segue prioritariamente a congruência semântica" [6, p. 101]. O fato da equivalência referencial nem sempre coincidir com a congruência semântica, torna-se, para muitos alunos, um obstáculo nas aprendizagens matemáticas.

O problema da congruência ou da não congruência semântica de duas representações semióticas, para um mesmo objeto matemático, refere-se à distância cognitiva entre essas duas representações. Quanto maior a distância cognitiva, maior será também o custo da passagem de uma representação semiótica a outra, e também, maior será o risco do processo matemático não ser efetuado ou entendido pelos alunos. Moretti [14] aponta para os reflexos da congruência semântica no ensino:

Problemas discursivos que são semanticamente congruentes com a expressão matemática, mas que não são referencialmente equivalentes, levam a uma taxa muita baixa de sucesso; da mesma forma acontece com problemas que são referencialmente equivalentes, mas não são semanticamente congruentes. A resolução de problemas que solicitam a passagem de um registro 
discursivo para um registro aritmético ou algébrico exige a equivalência referencial $[14$, p. 705$]$.

Nas situações de ensino, o professor deve estar atento ao fato de que nem sempre a congruência semântica conduz a resultados bem sucedidos na resolução de problemas matemáticos, e que, produzindo diferentes formulações para um mesmo problema, poderá, dessa forma, contribuir para uma verdadeira compreensão matemática.

Os fenômenos de não congruência semântica são mais numerosos que os fenômenos de congruência. É isso que faz a riqueza criadora da diversidade de registros. Eles não são previsíveis, mas devem ser estudados caso a caso, para cada atividade ou cada problema que propomos [7, p. 124].

Portanto, não devemos fugir dos problemas em que a congruência semântica não coincide com a equivalência referencial, pelo contrário, são eles que possibilitam o gesto intelectual tão necessário na aprendizagem da matemática.

Duas condições preliminares e indispensáveis devem ser atendidas para que alguém possa compreender e fazer qualquer coisa em matemática: reconhecer as unidades de sentido (dados matemáticos relevantes) e delinear as transformações dessas unidades de sentido (tratamentos ou conversões) [7]. O gesto intelectual de substituir uma representação semiótica por outra é um processo essencial para o pensamento matemático. A análise do funcionamento cognitivo do pensamento, exigida pela matemática, aponta para a necessidade da mobilização e coordenação de diversos registros para poder compreender.

Em outras palavras, em matemática, não pensamos jamais em um único registro, mas em vários ao mesmo tempo, mesmo se as produções vão privilegiar um único registro. $E$ isso requer uma atividade incessante de conversões, que ficam implícitas, mas que devem ser mais ou menos espontâneas [7, p. 116, grifos do autor].

Dois fenômenos podem ser observados, no que se refere à natureza cognitiva, nas operações de conversão. Primeiramente, as variações de congruência semânticas, já expostas anteriormente, e a segunda diz respeito à heterogeneidade dos dois sentidos de conversão. "Nem sempre a conversão se efetua quando se invertem os registros de partida e de chegada" [8, p. 20]. Segundo [8], no ensino da matemática, na maioria das vezes, um sentido de conversão é privilegiado, reforçando a falsa ideia de que o treinamento realizado num sentido estaria automaticamente exercitando a conversão no outro sentido. "A conversão direta e a conversão inversa são duas tarefas cognitivas tão diferentes quanto subir ou descer um caminho íngreme na montanha" [7, p. 
118]. Ou seja, para que haja uma sinergia na coordenação entre os vários registros de representação, é necessário ter a capacidade de converter as representações nos dois sentidos e não apenas em um único.

Na maioria das vezes, os estudantes não conseguem perceber o mesmo objeto matemático representado em sistemas semióticos diferentes. Por exemplo, a representação do cálculo de uma adição de números relativos e a sua representação através de deslocamentos na reta numérica; dificilmente um aluno, em nível de ensino fundamental e até mesmo médio, consegue estabelecer as relações entre o cálculo e a sua representação geométrica na reta numérica, e vice-versa. Essa coordenação está longe de ser natural e observamos, então, o que [5] chama de um "isolamento de registros de representação" (p. 283). O aluno "enxerga" o objeto matemático apenas por um sistema de representação, mesmo após esses diferentes registros terem sido utilizados amplamente. Essa ausência de coordenação não impede toda a compreensão, mas esta compreensão limitada, que se dá através do monorregistro, conduz um trabalho às cegas onde o aluno não tem um controle do sentido do que é feito. [5] afirma que mudanças na escrita permitem mostrar propriedades diferentes de um mesmo objeto matemático, porém conservando a mesma referência.

Os diferentes registros de representação se completam, dando-nos uma melhor compreensão do objeto matemático. A aprendizagem de um objeto matemático tornase significativa quando o aluno, além de realizar os tratamentos em diferentes registros de representação, consegue, também, naturalmente converter um registro de representação em outro. Do ponto de vista cognitivo, a atividade de conversão é essencial na condução à compreensão [8].

[5] assegura, por meio da ideia central da sua teoria, que: "A compreensão (integral) de um conteúdo conceitual repousa sobre a coordenação de ao menos dois registros de representação, e esta coordenação se manifesta pela rapidez e a espontaneidade da atividade cognitiva de conversão" [5, p. 282]. A figura 2 ilustra esta hipótese.

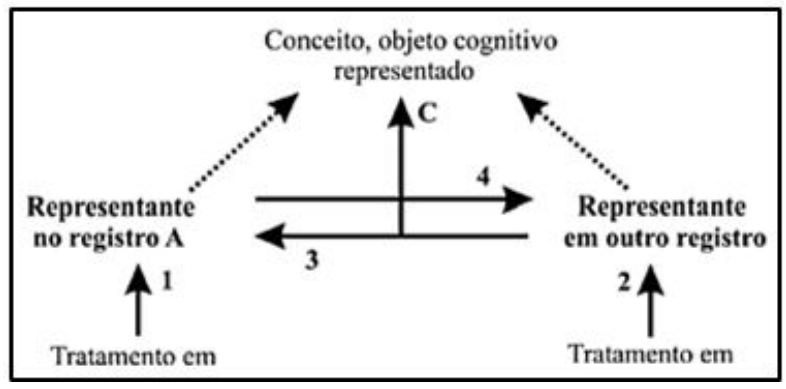

Figura 2: Hipótese fundamental de aprendizagem [5]

Na figura 2, as flechas 1 e 2 correspondem às transformações internas a um registro (tratamento) e as flechas 3 e 4 às transformações externas, ou seja, a mudança de re- 
gistro de representação (conversões). Com a flecha C, [5] apresenta uma coordenação de dois registros, correspondendo à compreensão integral de uma representação. As flechas pontilhadas marcam a distinção entre representante (conteúdo) e representado (objeto). Os tratamentos e as conversões são os dois grandes tipos de transformação de uma representação semiótica, eles constituem os gestos intelectuais.

O tratamento de uma representação é a transformação interna a um registro, ou seja, é a transformação dessa representação dentro do registro onde ela foi formada, sendo que, em cada registro, há regras de tratamentos próprios que variam em quantidade e natureza. A conversão é a transformação de uma representação dada em um registro, em uma representação de um outro registro, mantendo referência ao mesmo objeto, conservando a sua totalidade, ou apenas uma parte do conteúdo da representação inicial. Não podemos de forma alguma, confundir a conversão com o tratamento. A conversão se estabelece entre registros diferentes, enquanto o tratamento acontece dentro do mesmo registro. Contudo, essa coordenação não tem nada de natural e dificilmente um aluno reconhece o mesmo objeto matemático em registros diferentes. Para o caso dos inteiros relativos, dispomos de uma variedade de registros para representar um mesmo objeto. Por exemplo, a frase: "Pela manhã os termômetros registraram $-1^{\circ} \mathrm{C}$, com o passar do dia, as temperaturas subiram $5^{\circ} \mathrm{C}$ ", pode ser representada pela expressão $(-1)+(+5)$ e, também, por meio de um deslocamento na reta numérica:

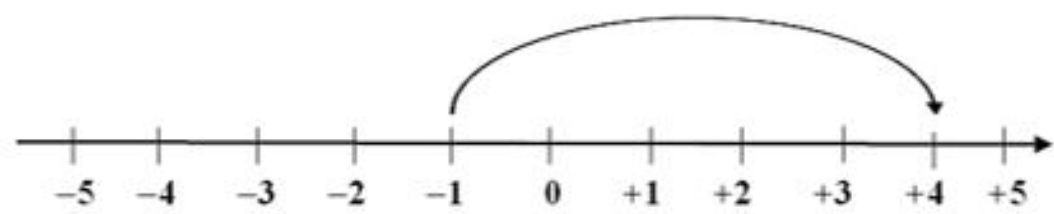

Figura 3: Representação geométrica da adição $(-1)+(+5)$

Neste exemplo, o mesmo objeto matemático é apresentado utilizando-se três registros de representação semiótica diferentes, a saber; a linguagem natural (discurso), registro simbólico (cálculo) e a representação geométrica (reta numérica). O aluno até pode conseguir representar esse objeto matemático nas três maneiras separadamente, mas muitas vezes pode ser incapaz de fazer as conversões necessárias para a apreensão desse objeto. Entretanto, Duval [8] afirma que a originalidade da atividade matemática está na mobilização simultânea de, ao menos, dois registros de representação, ou na possibilidade de trocar a todo o momento de registro de representação, uma vez que o principal papel da representação semiótica é que ela pode ser convertida em representações equivalentes em um outro sistema semiótico, que podem levar a significações diferentes pelo sujeito, de um mesmo objeto matemático.

Ao fazer uma análise do desenvolvimento dos conhecimentos e a dos obstáculos 
encontrados nas representações do raciocínio, [9] ressalta que os obstáculos encontrados pelos alunos na compreensão de textos e na aquisição de tratamentos lógicos e matemáticos podem ser compreendidos através dos três fenômenos que estão estreitamente ligados. O primeiro diz respeito aos vários registros de representação semiótica. No ensino da matemática, dispomos de uma variedade de registros de representação semiótica: a linguagem natural, a escrita simbólica, a configuração geométrica, os gráficos cartesianos. Esses registros não podem ser considerados como um mesmo tipo, eles são sistemas de representações muito diferentes que atuam cada um, de maneira específica sobre a aprendizagem. No exemplo da figura 3, na frase: "Pela manhã os termômetros registraram $-1^{\circ} \mathrm{C}$, com o passar do dia, as temperaturas subiram $5^{\circ} \mathrm{C}$ ", temos a produção do registro discursivo que implica na designação do objeto matemático com o propósito de enunciar um deslocamento na reta numérica. Esse tipo de registro, a língua natural, não permite efetuar tratamentos, como aqueles que podem ser realizados por meio do registro simbólico $(-1)+(+5)$, resultando em +4 , ou por meio do registro geométrico com o deslocamento na reta numérica, saindo do $(-1)$ e deslocando-se 5 espaços à direita, chegando no ponto +4 (resultado da operação). Cada uma dessas diferentes representações semióticas exibem sistemas semióticos diferentes. "As representações não são somente necessárias para fins de comunicação, elas são igualmente essenciais à atividade cognitiva do pensamento" [5, p. 269], desempenhando um papel importante no desenvolvimento das representações mentais, na realização de diferentes funções cognitivas e na produção de conhecimentos.

O segundo fenômeno, refere-se à diferenciação entre o representante e o representado; em outras palavras, a diferença existente entre a forma e o conteúdo de uma representação semiótica [9]. A forma escolhida para representar o objeto matemático influencia no conteúdo da sua representação. No exemplo descrito acima, a representação do objeto matemático por meio da reta numérica explora os aspectos geométricos, ao passo que a representação que utiliza a escrita simbólica trata dos cálculos possíveis de serem realizados. Isso mostra que duas expressões podem fazer referência a um mesmo objeto, porém elas não possuem a mesma significação, haja vista que elas não são reveladoras do mesmo domínio de descrição. As diferentes formas de representar um objeto matemático permitem exibir propriedades diferentes desse objeto mantendo a mesma referência. A decisão para escolher o registro semiótico "[. . .] para representar um conteúdo (objeto, conceito ou situação) impõe uma seleção de elementos significativos ou informacionais do conteúdo que representa. Esta escoIha é feita em função das possibilidades e dos inconvenientes semióticos do registro escolhido" [5, p. 280].

No exemplo citado acima, ilustrado pela figura 3, podemos perceber que apesar de 
os três registros utilizados representarem o mesmo objeto, eles possuem significações diferentes. Isso porque, mudar de registro de representação "[. . .] não é só mudar o conteúdo da representação de um objeto, é mudar as operações semióticas a realizar para transformar o conteúdo da nova representação" [7, p. 73]. As representações são cognitivamente parciais, pois de um registro a outro não são explorados os mesmos aspectos do conteúdo. Essa complementariedade de registros possibilitará a ideia global do objeto matemático, permitindo que o aluno não confunda o objeto matemático com a sua representação [5].

O terceiro fenômeno diz respeito à coordenação entre os diferentes registros de representação semiótica. Para efetuar a conversão de um sistema semiótico num outro sistema semiótico, não bastam regras de correspondência, mesmo porque se existisse uma regra não seria conversão. O maior obstáculo que se instala na realização espontânea da coordenação dos diferentes registros de representação semiótica está relacionado ao fenômeno da não congruência semântica. No exemplo que citamos anteriormente, dificilmente um aluno estabelece uma relação direta entre o cálculo $(-1)+(+5)$ e a sua representação na reta numérica, expresso pela figura 3. A expressão numérica possui congruência semântica com a movimentação apresentada na figura 4.

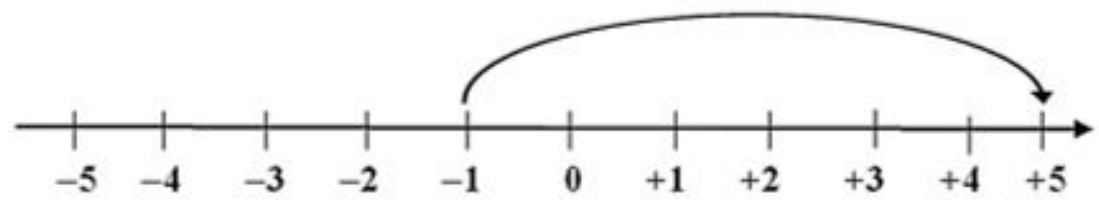

Figura 4: Congruência semântica entre cálculo e deslocamento na reta

Entretanto, a representação simbólica e a representação geométrica não são referencialmente equivalentes. Esse cálculo não possui congruência semântica com a representação geométrica da figura 3, pois na expressão numérica o deslocamento de 5 unidades para a direita impulsiona chegar no ponto +5 e não no +4 . Contudo, a expressão numérica é referencialmente equivalente a representação geométrica da figura 3, apesar de não possuírem congruência semântica.

Para analisarmos as dificuldades encontradas no processo de ensino e aprendizagem da matemática, precisamos estudar a conversão das representações, considerando os fenômenos da congruência e da não congruência semântica. A articulação de diferentes registros de representação semiótica é uma condição necessária para a compreensão em matemática. No entanto, várias abordagens didáticas não levam isso em conta, porque o que chama a atenção nos processos de ensino são os tratamentos e não a conversão [8].

Preocupando-se com as situações em que a equivalência referencial destaca-se 
da congruência semântica no processo de ensino e aprendizagem da regra dos sinais, [12] apresenta uma intervenção didática, em que o ensino dessa regra para uma turma do $7^{\circ}$ ano do ensino fundamental foi conduzido atendendo ao princípio de extensão ${ }^{3}$ [2], evitando o modelo comercial e atentando para os fenômenos da congruência e da não congruência semântica. Os resultados apresentados, na pesquisa desenvolvida pela autora, foram promissores, capazes de apontar novos caminhos para o ensino da regra dos sinais nesse nível de ensino.

\section{ALGUNS CASOS QUE DEMONSTRAM A PRESENÇA DO MODELO CO- MERCIAL E DA CONGRUÊNCIA SEMÂNTICA NO ENSINO DA REGRA DOS SINAIS}

Apresentaremos agora alguns dos achados de [12] e [11], a partir da aplicação de testes a alunos do $7^{\circ}$ ano do ensino fundamental. Os resultados encontrados por [12] foram decorrentes do desenvolvimento de uma sequência didática, na qual o ensino da regra dos sinais foi conduzido evitando-se o modelo comercial e atentando-se para os fenômenos da congruência semântica. Em [11], encontram-se os resultados da aplicação de questões envolvendo as operações de adição e multiplicação com números inteiros relativos a duas turmas do $7^{\circ}$ ano.

Uma turma foi aquela em que [12] desenvolveu a sequência didática, já na outra turma o ensino dessas operações foi conduzido por outro professor que não tinha a preocupação de evitar o modelo comercial e nem propor a regra dos sinais por meio de generalizações.

Uma das questões aplicadas por [11] aos alunos do $7^{\circ}$ obteve um índice de acertos de $80 \%$. A referida questão consistia em responder a situação: "Joana ganha 40 reais de sua mãe. Compra um livro por 30 reais. Seu pai Ihe dá 8 reais. Joana vai ao cinema e gasta 13 reais. a) Escreva uma expressão numérica que represente o saldo de Joana. b) Qual é o saldo de Joana?"

Os sucessos dos resultados alcançados pelos alunos, para essa questão, podem ser analisados na perspectiva do conforto e da segurança que o modelo comercial propicia. Os verbos ganhar e dar podem ser associados, sem nenhum constrangimento, aos números positivos. As ações de comprar e gastar podem corresponder aos números negativos. Assim, o saldo de Joana emerge num contexto financeiro, característico do modelo comercial, como denominado por [10]. Contudo, essa associação "codifi-

\footnotetext{
${ }^{3} \mathrm{~A}$ capacidade que o homem civilizado tem para fazer generalizações e abstrações, Caraça chama de "princípio de extensão". "[. . .] o homem tem tendência a generalizar e entender todas as aquisições do seu pensamento, seja qual for o caminho pelo qual essas aquisições se obtêm, e a procurar o maior rendimento possível dessas generalizações pela exploração metódica de todas as suas consequências. Todo o trabalho intelectual do homem é, no fundo, orientado por certas normas, certos princípios. Aquele princípio em virtude do qual se manifesta a tendência que acabamos de mencionar, daremos o nome de princípio de extensão" [2, p. 10].
} 
cada", que no momento é muito confortável, poderá trazer dificuldades na resolução dos problemas multiplicativos.

Analisando o número expressivo de acertos dessa questão, sob a ótica da congruência semântica, percebe-se a correspondência semântica entre as unidades significativas da frase e da expressão $(+40)+(30)+(+8)+(13)$; a univocidade "semântica" em que para cada ação de partida corresponde a um só registro de chegada. A ordem das unidades significativas entre os registros de partida (frase) e de chegada (expressão numérica) são mantidas. Neste caso, além de haver a congruência semântica entre a frase e o registro simbólico, existe também a equivalência referencial.

Contrariando o sucesso obtido pelos alunos para essa questão, Hillesheim e Moretti [11] ao aplicarem uma situação que envolveu a manipulação de dados não congruentes, encontraram uma taxa de apenas $17 \%$ de acertos. Foi solicitado aos alunos que escrevessem uma expressão numérica que representasse os movimentos realizados na reta numérica, tomando como ponto de partida o -4 , como ilustrado pela figura 5 .

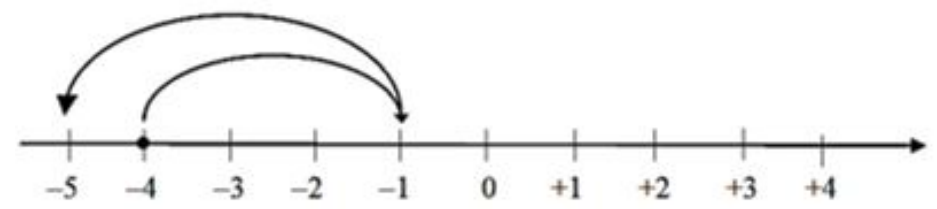

Figura 5: Movimentações realizadas na reta numérica [11]

Percebe-se que, para esta questão, recorrer ao modelo comercial não será o caminho mais promissor para resolvê-la. Logo, aquele conforto apresentado pela questão discutida anteriormente, sai de cena. A necessidade de adentrar numa linguagem matemática mais formal torna-se necessária para a solução desse problema. Compreender a disposição dos números inteiros relativos na reta numérica e as possíveis movimentações sobre ela fazem parte de um conhecimento matemático escolar.

Uma das possíveis causas para o baixo percentual de acertos encontrados, para essa questão, pode estar relacionada ao fato de não haver congruência semântica entre os movimentos propostos pelas setas na reta numérica e o seu registro numérico. No momento em que é realizada a conversão do registro geométrico para o registro numérico a congruência semântica impulsiona para a expressão numérica $(-4)+(-1)+(-5)$, correspondendo aos pontos de partida e de chegada das setas em movimento. No entanto, a equivalência referencial indica que, partindo do -4 , houve um deslocamento de 3 unidades para a direita $(+3)$ e, em seguida, um deslocamento de 4 unidades para a esquerda ( -4 ) chegando ao resultado da expressão, -5 . Logo, a movimentação geométrica, realizada na reta numérica, possui equivalência referencial com a expressão $(-4)+(+3)+(-4)=-5$.

Ao observarmos esse último exemplo, em relação ao precedente, notamos que 
ele mostra a não congruência semântica como uma possível fonte de dificuldades na resolução dos problemas matemáticos.

[...] uma atividade matemática pode ser bem sucedida se a sua apresentação e seu desenvolvimento não exigir alguma transformação entre as expressões de formulações ou de representações congruentes e, a mesma tarefa matemática dada com uma variante que implique manipulação de dados não congruentes, pode conduzir ao insucesso [6, p. 110].

$\mathrm{Na}$ tentativa de amenizar as dificuldades encontradas no processo de ensino e de aprendizagem da regra dos sinais, [12] elaborou e aplicou uma sequência didática em que as operações de adição, multiplicação e subtração de números inteiros foram apresentadas de acordo com o "princípio de extensão" [2], evitando o modelo comercial e possibilitando a aprendizagem da regra dos sinais por meio de generalizações. Como resultado da aplicação da sequência didática, [12] destaca que o ensino da adição dos números inteiros relativos, conduzido por meio de deslocamentos sobre a reta numérica, proporcionou aos alunos uma aprendizagem desprendida de regras préestabelecidas, como aquelas: "Sinais iguais soma-se e conserva o sinal" e "Sinais diferentes diminui-se e conserva o sinal do número de maior valor absoluto". A autora relata que os alunos, por meio das movimentações realizadas na reta numérica, foram capazes de sinalizar a formação de generalizações a respeito da regra dos sinais para a adição de números inteiros, contribuindo para que a confusão entre as regras dos sinais da adição e da multiplicação fossem quase extintas, tendo em vista que essas regras foram construídas num processo de generalizações e não pela imposição de regras preestabelecidas.

Comparando as justificativas apresentadas pelos alunos que participaram da sequência didática (turma A), desenvolvida por [12] com os alunos da turma em que o processo de ensino da regra de sinais não vislumbrou a possibilidade de generalizações (turma B) [11], percebemos que na turma B nenhum aluno apresentou como justificativa, para o cálculo $(-32)+(-16)$, o deslocamento sobre a reta numérica. Segundo os autores, todas as justificativas estiveram pautadas no modelo comercial ou em regras preestabelecidas, sendo evocadas como uma "poção mágica" que precisa ser seguida, mesmo sem ser compreendida [11]. Os autores ratificam essa situação apresentando algumas respostas encontradas, como, por exemplo, mostra-nos a figura 6.

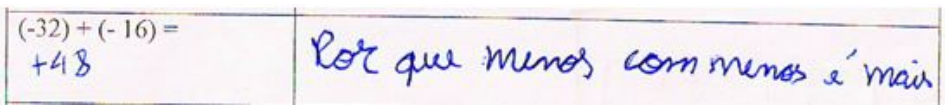

Figura 6: Resposta apresentada por aluno da turma B [11]

Na turma A, [12] indica que 53\% dos alunos dessa turma utilizaram a justificativa de deslocamentos sobre a reta numérica para resolver a operação $+12+(-5)$ e apenas 
um aluno apresentou como justificativa o modelo comercial. Vejamos um exemplo, ilustrado pela figura 7 .

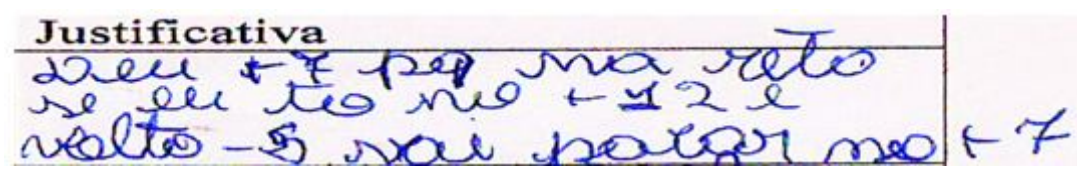

Figura 7: Resposta apresentada por aluno da turma A [12]

Amparados pela ideia de que adição de números inteiros pode ser resolvida por meio de deslocamentos sobre a reta numérica, a regra dos sinais para a multiplicação dos inteiros pode ser apresentada sem nenhum constrangimento, emergindo num processo natural como uma continuidade da adição [12]. Segundo a autora, a multiplicação de dois números positivos ou de um número positivo por um negativo seguiu a ideia de deslocamentos sobre a reta. Dessa maneira, os alunos, num processo de observação, de experimentação, de tentativas e erros, foram capazes de fazer generalizações, percebendo que a multiplicação de dois números negativos precisa ser positivo para atender às condições internas específicas da matemática, preservando a propriedade distributiva da multiplicação em relação à adição.

Contudo, apesar de todos os esforços para atingir os objetivos da pesquisa, [12] encontra um forte exemplo de como o modelo comercial cria obstáculo na compreensão das propriedades multiplicativas dos números negativos. A autora observa esse fenômeno por meio da justificativa apresentada por um dos alunos participantes da pesquisa, como mostra a figura 8.

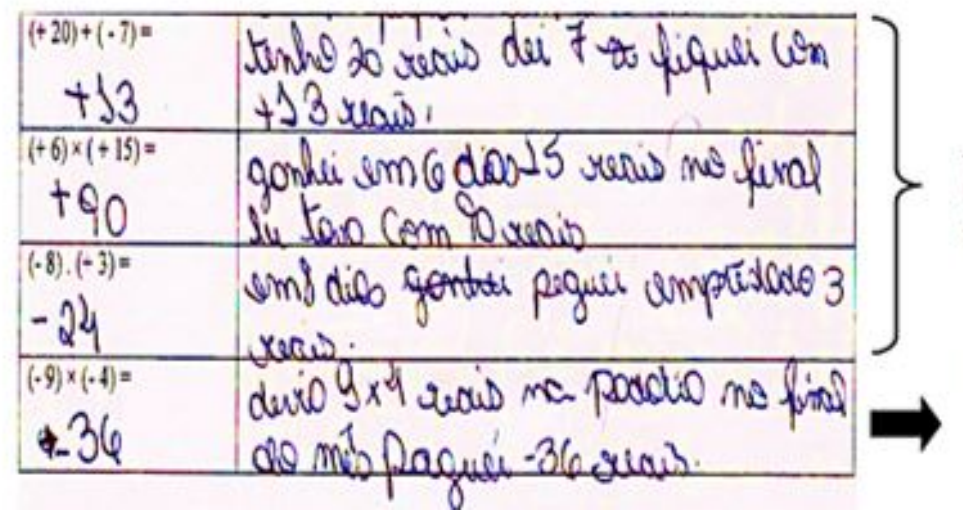

Aqui o modelo comercial funcionou para explicar as operaçōes.

Neste caso, o modelo comercial impediu o sucesso da resposta.

Figura 8: Resposta apresentada por aluno da turma A [12]

Este exemplo corrobora o que defendemos ao longo deste artigo. Apesar de toda uma sequência didática planejada por [12], buscando não enfatizar o modelo comercial, a concepção trazida por esse aluno de experiências anteriores, seja por situações vivenciadas socialmente, seja pela abordagem que essas operações tiveram no ano anterior $^{4}$, não foi capaz de ser abalada. O conforto e a conveniência de associar o

\footnotetext{
${ }^{4}$ Segundo Hillesheim [12] esse aluno estava cursando o $7^{\circ}$ ano pela segunda vez.
} 
número positivo e o número negativo a situações concretas, típicas do modelo comercial, serviram para explicar com sucesso as propriedades aditivas e até mesmo algumas multiplicativas, contudo encontrou obstáculos para explicar a multiplicação entre dois números negativos. Então, o modelo comercial que se adequava tão bem simplesmente deixou de funcionar. Percebemos que a resposta para a multiplicação $(-9) \times(-4)$, encontra-se rasurada, demonstrando o conflito gerado pelo modelo comercial para a multiplicação entre dois números negativos. Ou seja,

Essa concepção (na base concreta) não pode funcionar numa estrutura multiplicativa; é necessário revertê-la a fim de prosseguir a aprendizagem, mas ela está bem estabelecida, bem cômoda para resolver os problemas aditivos encontrados até aqui, que ela, nela mesmo, constitui um verdadeiro obstáculo para a instalação do nível IV ${ }^{5}$ [4, p. 184].

O modelo concreto que funciona muito bem para o ensino das propriedades aditivas, constitui-se como um entrave para o ensino das propriedades multiplicativas desses números. Ao que tudo indica, o modelo comercial se instalou definitivamente, não apenas como um modelo, mas como uma concepção dos relativos para esse aluno.

\section{CONCLUSÕES}

O presente artigo procurou mostrar que, apesar do problema da regra dos sinais ter sido solucionado matematicamente no século XIX, ainda encontramos, nos dias atuais, embaraços no campo metodológico para o seu ensino. Glaeser [10] mostra como um ensino pautado somente sobre exemplos concretos é nocivo. Sua defesa constitui-se numa "[. . .] bofetada dada à pedagogia das opiniões. Ela proclama, voluntariamente, que na matemática deve-se ensinar sobre exemplos concretos. A didática científica se esforça em colocar evidências, as vantagens e os inconvenientes de um ensino baseado sobre os exemplos" [10, p. 344]. Corroborando com essa defesa, Michelot [13] afirma que a ideia de número negativo só pode ser definida no campo das operações formais.

$\mathrm{Na}$ análise das respostas apresentadas pelos alunos envolvidos nas pesquisas de [12] e [11], observamos que quando os alunos estabelecem a concepção dos relativos em bases concretas, presa a exemplos práticos, provoca um conflito e um desconforto quando este é confrontado com a multiplicação entre dois números negativos. A regra dos sinais, quando apresentada de forma arbitrária, carente dos processos de produção e sistematização, favorece o surgimento da confusão entre as regras dos sinais da adição e da multiplicação.

\footnotetext{
${ }^{5} \mathrm{O}$ nível IV que Coquin-Viennot está referindo-se constitui a consolidação da concepção da multiplicação de números relativos.
} 
Concordamos com [12] ao defender que a introdução conceitual dos números inteiros relativos deve ser feita pela via formal, evitando as metáforas, que, com o intuito de facilitar a compreensão da sua estrutura, conduz os alunos à formação de ideias inconsistentes acerca dos inteiros relativos. É preciso conduzir o processo de ensino e aprendizagem desses números visando à concepção formal, para tanto, faz-se necessário o desapego a exemplos concretos.

As questões propostas por [11] e [12], que exigiram uma conversão de registros, nem sempre foram resolvidos com sucesso. Na atividade em que a congruência semântica convergiu para a equivalência referencial, obteve-se um número significativamente maior de acertos em comparação aos resultados apresentados a questão em que a congruência semântica destacou-se da equivalência referencial. O índice de acertos para esses dois tipos de atividades caiu consideravelmente, passando de $80 \%$ para 17\%, respectivamente. Entretanto, não há porque fugir de problemas sem congruência semântica, pois são eles que constituem o gesto intelectual tão necessário na resolução de problemas em matemática.

Um caminho possível para amenizar as dificuldades encontradas pelos alunos, nos casos em que a conversão é exigida, porém a congruência semântica destaca-se da equivalência referencial, é propor diferentes formulações coordenadas para um mesmo tipo de problema. A variedade de registros de representação semióticas, utilizados para o ensino das operações com números inteiros relativos, poderá contribuir para que o aluno tenha uma ideia global a respeito dessas operações, permitindo que a concepção dos relativos seja construída no campo das operações formais.

\section{REFERÊNCIAS}

[1] G. Bachelard, A formação do espírito científico: contribuição para uma psicanálise do conhecimento, Tradução Estela dos Santos Abreu, Contraponto, Rio de Janeiro, 1996.

[2] B. J. Caraça, Conceitos fundamentais da matemática, Bertrand, Lisboa, 1963. [Google Scholar]

[3] E. Cid, Obstáculos epistemológicos em la ensenãnza de los números negativos, in: Jornadas del Seminário Interuniversitario de Investigación em Didática de lãs Matemáticas, Boletin Del SI-IDM, Vol. 10., 2000, pp. 1-15. http://www.ugr.es/-jgodino/siidm/cangas/Negativos.pdf (Acesso 15 set 2012)

[4] D. Coquin-Viennot, "Complexité mathématique et ordre d'aquisition : une hierarchie de conceptions à propos des relatifs,"RDM, Vol. 6, № 2-3, 1985, pp. 133-192. [Google Scholar]

[5] R. Duval, "Registros de representação semiótica e funcionamento cognitivo do pensamento," Revemat, Vol. 7, №. 2, 2012a, pp. 266-297. [CrossRef] [Google Scholar]

[6] R. Duval, "Diferenças semânticas e coerência matemática: introdução aos problemas de congruência," Revemat, Vol. 7, №.1, 2012b, pp. 97-117. [CrossRef] [Google Scholar]

[7] R. Duval, Ver e ensinar a Matemática de outra forma: entrar no modo matemático de pensar os registros de representações semióticas, Tradução de Marlene Alves Dias, PROEM, São Paulo, 2011. 
[8] R. Duval, Registros de representação semiótica e funcionamento cognitivo da compreensão em matemática, in: S. A. Machado, Aprendizagem em matemática, Papirus, São Paulo, 2005, pp. 11-33.

[9] R. Duval, Semiosis y pensamiento humano: Registros semióticas y aprendizajes intelectuales, Peter Lang, Colombia, 2004.

[10] G. Glaeser, "Epistemologie des nombres relatifs,"RDM, Vol. 2, №. 3, 1981, pp. 303-346.

[11] S. F. Hillesheim, M. T. Moretti, "Modelo Comercial: um entrave persistente à aprendizagem da regra de sinais," REnCiMa, Vol. 4, №.2, 2013, pp. 37-56. [Google Scholar]

[12] S. F. Hillesheim, Os números inteiros relativos em sala de aula: perspectivas de ensino para a regra de sinais, dissertação de mestrado, Universidade Federal de Santa Catarina, Programa de Pós-Graduação em Educação Científica e Tecnológica, 2013.

[13] A. Michelot, La notion de zero, Flammarion, Paris, 1969.

[14] M. T. Moretti, "A regra dos sinais para a multiplicação: ponto de encontro com a noção de congruência semântica e o princípio de extensão em matemática," Bolema, Vol. 26, № 42B, 2012, pp. 691-714. [CrossRef] [Google Scholar]

[15] M. O. Pontes, Obstáculos superados pelos matemáticos no passado e vivenciados pelos alunos na atualidade: a polêmica multiplicação de números inteiros, tese de doutorado, Universidade Federal do Rio Grande do Norte, Programa de Pós-Graduação em Educação, 2010.

\section{BREVE BIOGRAFIA}

Selma Felisbino Hillesheim (D) https://orcid.org/0000-0001-6919-442X

Doutoranda no Programa de Pós-Graduação em Educação Científica e Tecnológica/ UFSC, Professora de Matemática na Rede Pública Estadual de Educação de Santa Catarina.

Méricles Thadeu Moretti (D) https://orcid.org/0000-0002-3710-9873

Doutor em Educação Matemática, Professor Titular em exercício voluntário na Universidade Federal de Santa Catarina - UFSC. Professor Permanente do Programa de Pós-Graduação em Educação Científica e Tecnológica - PPGECT/UFSC. 